DOI: 10.12957/demetra.2016.16543

\title{
Avaliação da rotulagem de alimentos à base de cereais para a alimentação de lactentes e crianças na primeira infância
}

\section{Evaluation of food labeling of cereal food for infants and children in early childhood}

\author{
Leontina Fernandes Britto ${ }^{1}$ \\ Antônio de Pádua Valença da Silva² \\ Luana Guabiraba Mendes ${ }^{3}$ \\ Stella Regina Arcanjo Medeiros ${ }^{4}$ \\ 'Universidade Estadual do Ceará, Programa de \\ Pós-graduação em Nutrição e Saúde. Fortaleza- \\ CE, Brasil. \\ 2Universidade Estadual do Ceará, Curso de \\ Nutrição, Curso de Especialização em Ciência de \\ Alimentos. Fortaleza-CE, Brasil. \\ ${ }^{3}$ Universidade Estadual do Ceará. Programa \\ de Pós-graduação da Rede Nordeste de \\ Biotecnologia. Fortaleza-CE, Brasil. \\ ${ }^{4}$ Universidade Federal do Piauí, Curso de Nutrição. \\ Picos-Pl, Brasil. \\ Correspondência / Corrrespondence \\ Leontina Fernandes Britto \\ E-mail: leontinafbritto@hotmail.com
}

\section{Resumo}

Objetivo: Avaliar a informação nutricional e a rotulagem de alimentos à base de cereais destinados à alimentação de lactentes e crianças na primeira infância, de acordo com a legislação vigente. Materiais e Métodos: Foram verificados 30 rótulos de produtos, sendo 25 marcas de farinha de cereais, quatro de bebida pronta para o consumo e uma marca de papinha pronta, captados por livre acesso em três supermercados de grande porte em Fortaleza-CE. Os rótulos foram fotografados e analisados através de uma lista de verificação com itens das Resoluções da Diretoria Colegiada n's 259/02, 360/03, 222/02, Portarias n's $36 / 98$ e 29/98, e Lei n ${ }^{\circ} 11.265 / 06$. Os dados obtidos foram agrupados em um banco de dados e estatisticamente analisados de forma descritiva. Resultados: Foram observadas 12 não conformidades que abrangiam a rotulagem de alimentos embalados, a informação nutricional, o regulamento técnico referente a alimentos à base de cereais para alimentação infantil e a Norma Brasileira de Comercialização de Alimentos para Lactentes, Crianças de Primeira Infância. Conclusão: Com o percentual de não conformidade reduzido, seriam necessários mais estudos para elucidar ainda mais essa problemática, o aumento da fiscalização deste tipo de produto, como também a implantação de ações educativas que ajudem os pais e cuidadores a reconhecerem melhor os produtos adequados a seus filhos, através do conhecimento do rótulo desses produtos.

Palavras-chave: Alimentação Infantil; Informação Nutricional; Rotulagem de Alimentos. 


\section{Abstract}

Objective: To evaluate the nutritional information and labeling of cereal food for infants and children in early childhood in accordance with current legislation. Materials and Methods: We checked 30 product labels, being 25 cereal flour brands, four beverages ready for consumption and a ready baby food brand, acquired by free access in three large supermarkets in Fortaleza, Ceara state, Brazil. The labels were photographed and analyzed through a checklist of items of the Collegiate Board Resolutions n. 259/02, 360/03, 222/02, Decrees n. 36/98 and 29/98, and Law n. 11265/06. Data were grouped into a database and statistically analyzed in a descriptive way. Results: We observed 12 nonconformities concerning labeling of packaged foods, nutrition information, technical regulation of cereal-based foods for babies and the Brazilian Standard for Food Commercialization of Infant and Young Child. Conclusion: Given the reduced nonconformity percentage, it would take more studies to elucidate this problem, increase monitoring of this type of product, as well as implementing educational activities to help parents and caregivers to better recognize the right products to their children, through the label knowledge of these products.

Key words: Child Nutrition; Nutritional Facts; Food Labeling.

\section{Introdução}

Com a disseminação da importância de uma alimentação saudável nos mais diversos meios de comunicação, tem-se observado o interesse sobre o consumo de carboidratos e fibras alimentares, que estão presentes em vários alimentos como raízes, tubérculos, frutas, cereais, entre outros. ${ }^{1}$

Os cereais são grãos provenientes das gramíneas cujas sementes dão em espigas como arroz, milhos, trigo, aveia, sorgo, cevada e quinoa. São utilizadas para alimentação desde as mais remotas civilizações, sendo importantes para a alimentação humana, pois constituem um alimento concentrado e fornecem em maior quantidade carboidratos, proteínas e fibras, além de serem de fácil conservação. ${ }^{2}$

O Ministério da Saúde, através dos Dez passos para uma alimentação saudável: guia para crianças menores de dois anos, recomenda que após os seis meses, sejam dados alimentos complementares como cereais, tubérculos, carnes, leguminosas, frutas e legumes. Se a criança ainda estiver sendo amamentada, a frequência de consumo desses alimentos deve ser de três vezes ao dia; e se a criança estiver desmamada, a frequência de consumo deve ser de cinco vezes ao dia. ${ }^{3}$ 
Segundo a Lei n 11265/2006, os alimentos à base de cereais para lactentes e crianças de primeira infância são "qualquer alimento à base de cereais próprio para a alimentação de lactentes após o 6o (sexto) mês e de crianças de primeira infância, respeitando-se sua maturidade fisiológica e seu desenvolvimento neuropsicomotor". ${ }^{4}$ Com o aumento da participação da mulher no mercado de trabalho, muitas mães que estão presentes neste grupo se vêm obrigadas a introduzir precocemente fórmulas infantis, leite integral, alimentos complementares e cereais na alimentação dos seus bebês para poderem voltar a trabalhar.

Percebendo esta necessidade das mães, a indústria de alimentos tem desenvolvido cada vez mais produtos destinados a lactentes e crianças de primeira infância e tem utilizado do marketing para promover esses produtos. ${ }^{5,6}$ Estudos têm observado aumentos do consumo desses alimentos pela população infantil, como foi o observado por Sousa \& Araújo, ${ }^{7}$ que analisaram o padrão alimentar de crianças de seis a 24 meses em área rural do Maranhão. Os autores perceberam que o leite materno associado a mingau de cereais são os únicos alimentos para13,5\% das crianças estudadas e também viram que o mingau de cereal apareceu como opção alimentar para 74 crianças, das quais 46(39\%) o utilizavam como única forma alimentar.

Farias Junior \& Osório, ${ }^{8}$ pesquisando o padrão alimentar de crianças menores de cinco anos no Estado de Pernambuco, observaram que os alimentos à base de cereais apresentavam percentuais decrescentes de consumo com a elevação da idade a partir dos seis meses de idade, mas quanto à renda, o consumo de alimentos à base de cereais mostrou-se positivamente associado, sendo que no grupo de maior renda os alimentos à base de cereais foram consumidos por 40,1\% das crianças.

Com base nestas informações, o presente estudo tem como finalidade avaliar a informação nutricional, a rotulagem e o atendimento à Norma Brasileira de Comercialização de Alimentos para Lactentes, Crianças de primeira Infância, Bicos, Chupetas e Mamadeiras (NBCAL) de alimentos à base de cereais destinados à alimentação de lactentes e crianças na primeira infância. Estes compõem parcela significativa da alimentação dessa população, assim esta pesquisa contribuirá para a verificação aplicação da legislação vigente destinada a esse tipo de alimento.

\section{Metodologia}

Trata-se de pesquisa quantitativa, descritiva e transversal, que avaliou a adequação da comercialização dos alimentos à base de cereais destinados a lactentes e crianças na primeira infância em três supermercados de grande porte de Fortaleza-CE, nas duas primeiras semanas do mês de setembro de 2014, observando adequação quanto a rotulagem, informação nutricional, à Norma Brasileira de Comercialização de Alimentos para Lactentes, Crianças de primeira Infância, Bicos, Chupetas e Mamadeiras (NBCAL) e ao Regulamento Técnico referente a alimentos à base de cereais para alimentação infantil destes produtos. 
Para a coleta de dados, foram observados e fotografados em cada supermercado visitado todos os alimentos dentro dos critérios estabelecidos. Foram observados, no total, 29 marcas, sendo 25 de farinha de cereais, quatro marcas de bebida pronta para o consumo e uma de papinha pronta, que foram codificadas seguindo a ordem de coleta e utilizando duas letras e dois algarismos, conforme a tabela 1 .

Tabela 1. Codificação das amostras dos rótulos de alimentos à base de cereais para alimentação infantil. Fortaleza-CE, 2014.

\begin{tabular}{cc}
\hline PRODUTOS ANALiSADOS & Código DAS Amostras \\
\hline Farinha de cereais & FC01, FC02, FC03, FC04, FC05, FC06, \\
& FC07, FC08, FC09, FC10, FC11, FC12, \\
FC13, FC15, FC16, FC17, FC18, FC19, \\
FC20, FC21, FC22, FC23, FC24, FC25 \\
\hline Pebida pronta para o consumo & BP01, BP02, BP03, BP04 \\
\hline Papinha pronta & PP01
\end{tabular}

Como instrumento de coleta, foi utilizada a Lista de Verificação para Alimentos à Base de Cereal para Lactentes e Crianças de Primeira Infância, adaptada do estudo de Chater. ${ }^{9}$ A lista de verificação foi composta pelos seguintes itens: dados do produto (nome, código, marca e fabricante); rotulagem de alimentos embalados com base na RDC n ${ }^{\circ}$ 259, de 20 de setembro de 2002; informação nutricional com base na Resolução RDC n 360, de 23 de dezembro de 2003; regulamento técnico referente a alimentos à base de cereais para alimentação infantil, com base na Portaria n 36, de 13 de janeiro de 1998 e na Portaria no 29, de 13 de janeiro de 1998; e nas normas de comercialização de alimentos para lactentes e crianças na primeira infância, segundo a Lei n ${ }^{\circ} 11.265$, de 03 de janeiro de 2006 e Resolução RDC n ${ }^{\circ}$ 222, de 05 de fevereiro de 2002; e por fim, a Lei n ${ }^{\circ} 10.674$, de 16 de maio de 2003, que regulamenta a advertência sobre o glúten., ${ }^{4-10}$ As informações coletadas foram avaliadas de acordo com cada legislação regulamentar e classificadas em conforme(C), não conforme(NC) e não se aplica(NA). 


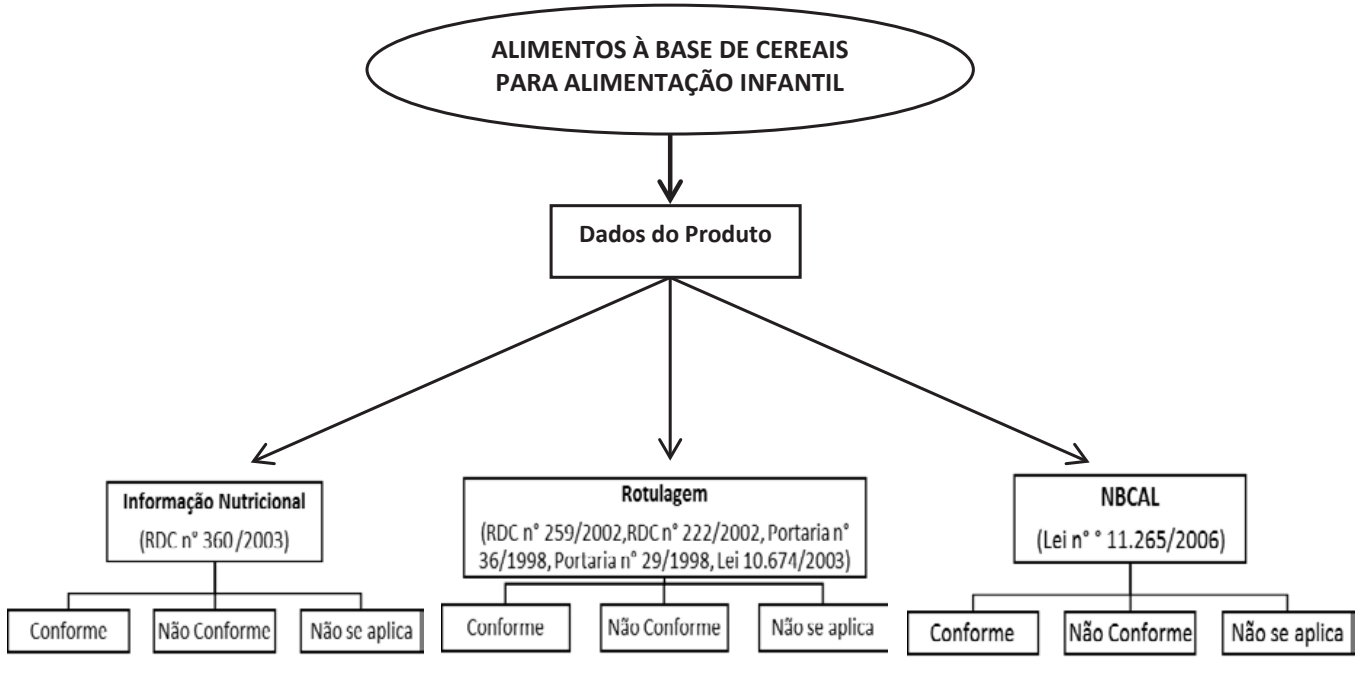

Figura 1. Organograma da análise dos dados coletados. Fortaleza-CE, 2014

Os dados obtidos foram agrupados em um banco de dados e estatisticamente analisados de forma descritiva com o software Excel 2013, com o qual também foram elaboradas tabelas.

\section{Resultados}

No presente estudo, foram avaliados 30 rótulos de alimentos à base de cereais para lactentes e primeira infância, dos quais foram observadas 12 não conformidades em 10 rótulos (tabela 2), somente em algumas marcas de farinha de cereais. Dentre as não conformidades, estavam informações obrigatórias, a informação nutricional, o regulamento técnico referente a alimentos à base de cereais para alimentação infantil e a Norma Brasileira de Comercialização de Alimentos para Lactentes, Crianças de Primeira Infância (NBCAL). 
Tabela 2. Adequação dos rótulos de alimentos à base de cereais para alimentação infantil, em conformidade com a legislação vigente. Fortaleza-CE, 2014.

\begin{tabular}{cccc}
\hline CRITÉRIOS ANALISADOS & $\mathrm{N}$ & $\%$ & Item de Não Conformidade \\
\hline Informações obrigatórias $(\mathrm{p}=0,046)$ & & & \\
\hline Conforme & 28 & 93,3 & \\
\hline Não Conforme & $2^{\text {a }}$ & 6,7 & Falta da origem do produto \\
\hline Informação nutricional $(\mathbf{p = 0 , 0 3 3 )}$ & & & \\
\hline Conforme & 29 & 96,7 & \\
\hline Não Conforme & $1^{\text {b }}$ & 3,3 & $\begin{array}{c}\text { Valor calórico não } \\
\text { informado }\end{array}$ \\
\hline
\end{tabular}

Regulamento técnico referente a

alimentos à base de cereais para

alimentação infantil $(p=0,074)$

\begin{tabular}{cccc}
\hline Conforme & 24 & 80,0 & \\
\hline Não Conforme & $6^{c}$ & 20,0 & Falta de lista de ingredientes \\
& & & após preparo \\
& & & $\begin{array}{c}\text { Sem denominação para } \\
\text { alimentação infantil }\end{array}$ \\
\hline
\end{tabular}

\section{Norma Brasileira de}

Comercialização de Alimentos para

Lactentes, Crianças de primeira

Infância, Bicos, Chupetas e

Mamadeiras (NBCAL) $(p=0,055)$

\begin{tabular}{cccc}
\hline Conforme & 27 & 90,0 & \\
\hline Não Conforme & $3^{\mathrm{d}}$ & 10,0 & $\begin{array}{c}\text { Especificação da Idade } \\
\text { Falta do texto informativo } \\
\text { do MS }\end{array}$ \\
\hline Advertência sobre o glúten & & & - \\
\hline Conforme & 30 & 100 & \\
\hline
\end{tabular}

a Marca 20 e 21;

${ }^{\text {b }}$ Marca 17;

${ }^{\text {c } M a r c a ~ 17,19, ~ 24, ~ 25, ~} 26$ e 27;

${ }^{d}$ Marca 18, 19 e 28; 


\section{Discussão}

As Resoluções de Diretoria Colegiada - RDC n 259/2003, que dispõe sobre o regulamento técnico sobre rotulagem de alimentos embalados, a RDC n 360/2003, que dispõe sobre o regulamento técnico sobre rotulagem nutricional de alimentos embalados - e a Lei n ${ }^{\circ}$ 10.674/2003, que obriga que os produtos alimentícios comercializados informem sobre a presença de glúten, são as base para a normatização da rotulagem no Brasil. ${ }^{10,11,15-17}$

O governo brasileiro, preocupado com a disseminação de produtos para lactentes e crianças de primeira infância e com a diminuição das taxas de aleitamento materno exclusivo, criou e aprovou, em 1988, a Norma para Comercialização de Alimentos para Lactentes (NBCAL), que regula a promoção comercial e a rotulagem de alimentos e produtos destinados a recém-nascidos e crianças até três anos de idade. ${ }^{18}$

Em 1992, realizou-se a primeira revisão da NBCAL, após vários monitoramentos e reuniões com diversos órgãos como a Agência Nacional de Vigilância Sanitária (ANVISA) e o Ministério Público, resultando na Portaria $n^{\circ} 2.051$, de 8 de novembro de 2001, que estabeleceu os novos critérios da NBCAL, na Resolução RDC n 222, de 5 de agosto de 2002, que regulamenta a promoção comercial dos alimentos para lactentes e crianças de primeira infância, e na Resolução RDC $\mathrm{n}^{\circ} 221$, de 5 de agosto de 2002, que regulamenta chupetas, mamadeiras e protetores de mamilos. Também foi publicado a Lei ${ }^{\circ} 11.265$, de 3 de janeiro de 2006, a qual regulamenta a comercialização de alimentos para lactentes e crianças de primeira infância, como também de produtos de puericultura e correlatos, fortalecendo assim a NBCAL. ${ }^{4,14,18-20}$

Sobre a rotulagem de alimentos embalados, observou-se que nos dois produtos analisados não estava descrita a origem do produto, ou seja, no rótulo não constavam informações sobre o fabricante, como estabelece a RDC n ${ }^{\circ}$ 259/2002. ${ }^{10}$ Dentre as informações obrigatórias no rótulo, deve constar a identificação de origem do produto através do nome (razão social) do fabricante ou produtor ou fracionador ou titular (proprietário) da marca; o endereço completo; país de origem e município e o número de registro ou código de identificação do estabelecimento fabricante junto ao órgão competente. Além disso, este deve ser utilizado para identificar a origem as expressões: "fabricado em... ", "produto ..." ou "indústria ...". Este fato foi também observado por Yoshizawa et al., ${ }^{16}$ que verificaram a ausência da denominação de venda em dez rótulos de alimentos infantis à base de cereais (determinação exigida pela RDC no 259/2002); e por Chater, ${ }^{9}$ que verificou a existência de 27 itens de não conformidade quanto à rotulagem dos 16 rótulos de alimentos infantis à base de cereais analisados. Dentre essas não conformidades, também faltava informação sobre a origem do produto.

Com relação à informação nutricional, apenas um produto não informou o valor calórico, e a RDC n ${ }^{\circ}$ 360/200211 declara que é obrigatório informar a quantidade do valor energético e dos 
nutrientes (carboidratos, proteínas, gorduras totais, gorduras saturadas, gorduras trans, fibra alimentar e sódio). No estudo de Smith \& Almeida-Muradian, ${ }^{17}$ que analisou a rotulagem de vários tipos de produtos, dentre os quais aqueles à base de cereais para alimentação infantil, os autores observaram que a tabela nutricional apresentou o maior número de não conformidades entre os itens avaliados, pois 26,9\% dos rótulos analisados apresentaram erros com relação à informação nutricional (informação nutricional complementar não correspondia à quantidade de nutriente presente no alimento; não atendimento aos critérios para utilização de informação nutricional complementar de gorduras trans e informação nutricional complementar diferente ou não prevista pela legislação). Já no estudo de Silva, Dias \& Ferreira ${ }^{18}$ esse fato não ocorreu, pois não foi encontrada nenhuma não conformidade no que tange às informações gerais obrigatórias nos rótulos.

Sobre a não adequação ao regulamento técnico referente a alimentos à base de cereais para alimentação infantil, observou-se que seis produtos analisados não estavam conforme a legislação. As não conformidades observadas foram: falta da denominação para alimentação infantil (que, conforme a Portaria n 36/1998, ${ }^{12}$ devem constar no painel principal a designação do produto "cereal ou cereais para alimentação infantil"); e a falta da lista de ingredientes após preparo. Segundo a mesma legislação, deve constar nos demais painéis da embalagem a lista completa dos ingredientes, em ordem decrescente da respectiva proporção; e quando o alimento necessitar ser consumido mediante adição de líquido, a lista deve ser encabeçada pela indicação "ingredientes após o preparo”, da qual não podem fazer parte os ingredientes dos líquidos adicionados. Entretanto, Vasconcelos ${ }^{19}$ observou que todos os produtos a alimentos à base de cereais para alimentação infantil estavam de acordo com a rotulagem específica.

Quanto à Norma Brasileira de Comercialização de Alimentos para Lactentes, Crianças de Primeira Infância, Bicos, Chupetas e Mamadeiras (NBCAL), regulamentada pela Lei no 11.265/06 e pela $\mathrm{RDC}^{\circ}$ 222/02, apenas três produtos apresentaram não conformidades, relacionadas à falta de especificação de idade do produto e não descrição do texto informativo do Ministério da Saúde. Segundo a legislação, devem constar no painel frontal dos rótulos desses produtos a idade a partir da qual eles poderão ser utilizados, bem como o texto informativo "O Ministério da Saúde adverte: Este produto não deve ser usado para crianças menores de 6 (seis) meses de idade, a não ser por indicação expressa de médico ou nutricionista. $\mathrm{O}$ aleitamento materno evita infecções e alergias e é recomendado até os 2 (dois) anos de idade ou mais", de forma legível e de fácil visualização.

Nos estudos de Smith \& Almeida-Muradian ${ }^{17}$ e Silva, Dias \& Ferreira, ${ }^{18}$ em Goiânia-GO; Paula, Chagas \& Ramos, ${ }^{20}$ em Teresina-PI, e Vasconcelos,${ }^{19}$ em Camaçari-BA, que analisaram a rotulagem de alimentos para lactentes e crianças de primeira infância, também foram observadas não conformidades em relação à NBCAL, dentre as quais também constavam: a não indicação da faixa etária, a ausência da frase obrigatória, o uso de ilustrações e frases não permitidas. Demonstraram, deste modo, o descumprimento dos critérios previstos na NBCAL. 


\section{Conclusão}

O presente estudo observou que maioria dos alimentos à base de cereais para lactentes e crianças de primeira infância cumpre a legislação, apesar de apresentarem 33\% de não conformidades. Este fato também foi observado em outros trabalhos; desta forma, mais estudos podem ser realizados para elucidar ainda mais essa problemática, como também aumentar a fiscalização deste tipo de produto.

Uma medida preventiva seriam ações educativas que ajudassem os pais e cuidadores a reconhecerem melhor os produtos adequados a seus filhos, através do conhecimento do rótulo desses produtos, que são muito utilizados nas refeições das crianças de primeira infância, devido a sua aceitabilidade e praticidade.

\section{Referências}

1. Almeida CAN, Fernandes GC. Cereais integrais na alimentação infantil. International Journal of Nutrology 2011; 4(3):46-52.

2. Ornelas LH. Técnica dietética: seleção e preparo de alimentos. $8^{\circ}$ ed. São Paulo: Atheneu; 2006. p. 135-156.

3. Brasil. Ministério da Saúde. Dez passos para uma alimentação saudável: guia alimentar para crianças menores de dois anos. Brasília: Ministério da Saúde; 2005.

4. Brasil. Lei n 11265 , de 3 de janeiro de 2006. Regulamenta a comercialização de alimentos para lactentes e crianças de primeira infância e também a de produtos de puericultura correlatos. Diário Oficial da União 4 jan. 2006; Seção 1, p 1-3.

5. Araújo MFM, Rea MF, Pinheiro KA, Shimitz BAS. Avanços na norma brasileira de comercialização de alimentos para idade infantil. Rev. Saúde Pública 2006; 40(3):513-520.

6. Junqueira JM, Navarro AM, Cintra RMGC, Dias LCGD. Padrão alimentar de menores de 2 anos: uma visão crítica. Rev. Simbio-Logias 2008; 1(1):184-199.

7. Sousa FGM, Araújo TL. Padrão alimentar de crianças de 6 a 24 meses em área rural do Maranhão. Acta Paul. Enferm. 2005; 18(2):172-177.

8. Farias Junior G; Osório MM. Padrão alimentar de crianças menores de 5 anos. Rev. Nutr. 2005; 18(6):793-802.

9. Chater MMF. Rotulagem de produtos destinados a lactentes e crianças de primeira infância. [Especialização]. [Brasília]: Universidade de Brasília; 2009.

10. Brasil. Resolução RDC ñ. 259, de 20 de Setembro de 2002. Regulamento Técnico para Rotulagem de Alimentos Embalados. Diário Oficial da União 23 set. 2002; Seção 1.

11. Brasil. Resolução RDC nº. 360, de 23 de dezembro de 2003. Regulamento Técnico sobra Rotulagem Nutricional de Alimentos Embalados. Diário Oficial da União 26 dez. 2003; Seção 1. 
12. Brasil. Portaria n $n^{\circ}$, de 13 de janeiro de 1998. Aprova o Regulamento Técnico referente a alimentos à base de cereais para alimentação infantil. Diário Oficial da União 16 jan. 1998; Seção 1.

13. Brasil. Portaria no. 29, de 13 de janeiro de 1998. Aprova o Regulamento Técnico referente a Alimentos para Fins Especiais. Diário Oficial da União 30 mar. 1998; Seção 1.

14. Brasil. Resolução RDC no 222, de 05 de janeiro de 2002. Regulamento Técnico para Promoção Comercial de Alimentos para Lactentes e Crianças de primeira infância. Diário Oficial da União 06 ago. 2002. Secção 1.

15. Brasil. Lei $\mathrm{n}^{\circ} 10.674$, de 16 de maio de 2003. Obriga a que os produtos alimentícios comercializados informem sobre a presença de glúten, como medida preventiva e de controle da doença celíaca. Diário Oficial União 19 mai. 2003; Seção 1.

16. Yoshizawa N, Pospissil RT, Valentim AG, Seixas D, Alves FS, Cassou F, et al. Rotulagem de alimentos como veículo de informação ao consumidor: adequações e irregularidades. Bol. Cent. Pesqui. Process. Alimen. 2003; 21(1):169-180.

17. Smith ACL, Almeida-Muradian LB. Rotulagem de alimentos: avaliação da conformidade frente à legislação e propostas para a sua melhoria. Rev. Inst. Adolfo Lutz 2011; 70(4):463-472.

18. Silva SA, Dias MRM, Ferreira TAP. Rotulagem de alimentos para lactentes e crianças de primeira infância. Rev. Nutr. 2008; 21(2):185-194.

19. Vasconcelos AC. Alimentos para lactentes e crianças de primeira infância: uma avaliação da rotulagem e do conteúdo de vitamina A e ferro. [Mestrado]. [Salvador]: Universidade Federal da Bahia; 2012.

20. Paulo LO, Chagas LR, Ramos CV. Monitoramento da norma brasileira de comercialização de alimentos infantis. Nutrire: Rev. Soc. Bras. Alim. Nutr. 2010; 35(3):43-55.

Recebido: 21/5/2015

Revisado: $12 / 10 / 2015$

Aceito: 16/1/2016 